\title{
RACISMO ESTRUTURAL: CONTRIBUIÇÕES DE SILVIO ALMEIDA PARA A CONSTRUÇÃO DE UMA SOCIEDADE ANTIRRACISTA
}

\section{STRUCTURAL RACISM: SILVIO ALMEIDA'S CONTRIBUTIONS TO THE CONSTRUCTION OF AN ANTI-RACIST SOCIETY}

\author{
Bruno Cesar Pereira ${ }^{1}$
}

\section{RESUMO}

O presente texto corresponde a uma resenha do livro Racismo Estrutural de autoria de Silvio Almeida. Em seu estudo o pesquisador realiza uma série de reflexões que buscam evidenciar as relações entre a racismo e as noções de raça, ideologia, política, direito e economia. Esta obra constitui-se como uma importante referência na atualidade, sobretudo no que toca os debates acerca da construção de uma sociedade antirracista.

Palavras-chaves: Racismo; Sociedade; História.

\section{ABSTRACT}

This text corresponds to a review of the book Structural Racism by Silvio Almeida. In his study, the researcher conducts a series of reflections that highlight the relationship between racism and the notions of race, ideology, politics, law, and economics. This work constitutes an important reference today, especially when it comes to debates about constructing an anti-racist society.

Keywords: Racism; Society; Story.

ALMEIDA, Silvio Luiz de. Racismo Estrutural. São Paulo: Ed. Jandaíra - Coleção Feminismo Plurais (Selo Sueli Carneiro), 2020.

Silvio Luiz de Almeida, paulista, advogado, filósofo e doutor em Direito, é uma das principais vozes do movimento intelectual negro do país dos últimos anos. Em sua obra, a qual resenharemos, este pesquisador se debruça sobre uma temática cara a sociedade brasileira, o racismo.

\footnotetext{
${ }^{1}$ Atualmente é Mestrando em História pela Universidade Estadual do Centro-Oeste do Paraná, Campus Irati. Bolsista pela Coordenação de Aperfeiçoamento de Pessoal de Nível Superior (CAPES). Graduado em História pela Universidade Estadual do Centro-Oeste do Paraná - UNICENTRO, Campus Irati. e-mail: bruno_o8cesar@outlook.com
} 


\section{Revista \\ Debates Insubmissos}

Racismo Estrutural, publicado em 2020 pela editora Jandaíra, é uma entre as sete obras da coleção Feminismo Plurais coordenado pela pesquisadora Djamila Ribeiro. Esta coleção, visa, segundo sua organizadora, disseminar conteúdos críticos produzidos por sujeitos negros, na busca de construir instrumentais para compreender a realidade e debates profundos no país. Entre os principais temas debatidos nesta coleção encontramos: encarceramento, racismo, branquitude, lesbiandades, transexualidades, empoderamento, masculinidades e interseccionalidades ${ }^{2}$. Como pontua Djamila Ribeiro, na apresentação da obra de Silvio Almeida,

[...] essa coleção é organizada e escrita por mulheres negras e indígenas, e homens negros de regiões diversas do país, mostrando a importância de pautarmos como sujeitos as questões que são essenciais para o rompimento da narrativa dominante e não sermos tão somente capítulos em compêndios que ainda pensam a questão racial como recorte (RIBEIRO, 2020 Apud ALMEIDA, 2020, p. 17).

Especificamente em Racismo Estrutural, Silvio Almeida alerta seus leitores que sua obra não trata-se apenas sobre raça ou racismo, mas sim de um estudo de teoria social. Almeida ressalta que a sociedade contemporânea não pode ser compreendida sem os conceitos de raça e racismo, neste sentido, o pesquisador ao longo deste profundo estudo demonstra como a filosofia, a ciência política, a teoria do direito e a teoria econômica "[...] mantêm, ainda que de forma velada, um diálogo com o conceito de raça" (ALMEIDA, 2020, p. 20).

Silvio Almeida defende a tese de que o racismo é sempre estrutural, ou seja, "[...] é um elemento que integra a organização econômica e política da sociedade" (ALMEIDA, 2020, p. 20-21). Sua proposta com esta investigação visa compreender que o racismo corresponde a uma manifestação normal das sociedades e não como um mero fenômeno patológico ou algo que corresponde a uma anormalidade.

\footnotetext{
${ }^{2}$ As demais obras e suas (eus) respectivas (os) autoras (es) que compõem a coleção Feminismo Plurais são: $O$ que é lugar de Fala? de Djamila Ribeiro, $O$ que é interseccionalidade de Carla Akotirene, $O$ que é racismo recreativo de Adilson Moreira, $O$ que é encarceramento de massa de Juliana Borges, Empoderamento de Joice Berth, e, por fim, Apropriação Cultural de Rodney William.
} 


\section{Revista \\ Debates Insubmissos}

Segundo Almeida (2020, p. 21): “[...] o racismo fornece sentido, a lógica e a tecnologia para a reprodução das formas de desigualdade e violência que moldam a vida social contemporânea".

Sua obra visa demonstrar que as expressões do racismo, ou seja, suas manifestações no cotidiano, nas relações interpessoais, nas dinâmicas das instituições, correspondem a manifestações de questões mais profundas, que, segundo o pesquisador, "[...] se desenvolvem nas entranhas políticas e econômicas da sociedade" (ALMEIDA, p. 21).

Seu livro encontra-se dividido em cinco partes. Sendo a primeira uma exposição histórico-conceitual dos termos raça e racismo, passando pelas discussões da classificação dos sujeitos (ao longo dos séculos XVI-XVIII) e desembocando nas teorias do racismo cientifico norteadas pelo darwinismo social dos séculos XIX e XX, analisando o pensamento de autores como Gobineua, Ferri e Lombroso, assim como salientando estas questões no contexto brasileiro a partir da análise da produção de pesquisadores como Silvio Romero e Raimundo Nina Rodrigues.

Silvio Almeida, destaca a partir destas analises que a "raça" corresponde a uma construção sócio-histórica, bem como é "[...] um elemento essencialmente político" (ALMEIDA, 2020, p. 31). Na construção de sua argumentação, o autor destaca que o conceito de racismo pode ser compreendido a partir de três abordagens, sendo elas: a individual, institucional e estrutural.

De um modo geral, sua argumentação na apresentação destas três abordagens visa evidenciar que o racismo deve ser compreendido a partir da terceira, ou seja, de ver concebido enquanto uma parte integrante da sociedade em sua forma estrutural, pois, para o pesquisador, o racismo deriva de uma estrutura da sociedade na qual normaliza, bem como concebe como verdade padrões uma série de regras baseadas em princípios discriminatórios de raça. Neste sentido, para Almeida o racismo é parte de um processo histórico, político e social que elabora uma série de mecanismos para que sujeitos e/ou grupos sejam discriminados de maneira sistemática. Assim, Almeida concebe o racismo enquanto regra e não exceção, da 


\title{
novitt

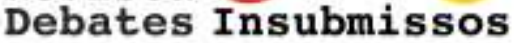

mesma forma, salienta que ao compreende-lo de forma individual, enquanto uma "patologia", corresponde, de certa forma, em deixar de lado o caráter histórico e cultural do racismo.

Nos quatro capítulos restantes que compõem sua obra, Silvio Almeida busca tecer e estabelecer a relação entre racismo e os aspectos centrais das estruturas sociais: racismo e ideologia (capítulo 2); racismo e política (capítulo 3); racismo e direito (capítulo 4) e racismo e economia (capítulo 5).

Como salienta Silvio Almeida, a ideologia, política, direito e economia, são os elementos cernes da manifestação estrutural do racismo,

\begin{abstract}
Nossa tese é de que o estudo do racismo não deve não deve ser desvinculado de uma análise sobre esses quatro elementos, mas o que sustentamos aqui vai também no sentido oposto: a ideologia, a política, o direito e a economia não devem prescindir do estudo do racismo. Portanto, a divisão da análise do racismo em quatro elementos estruturais é feita apenas para fins expositivos, dado que estamos tratando de um fenômeno social complexo (ALMEIDA, 2020, p. 57, grifos do autor).
\end{abstract}

Almeida, ao longo desta segunda parte de sua obra, nos quatro capítulos restantes, demonstra os modos como ocorrem a naturalização do racismo, destacando uma série de instâncias e instituições (como os meios de comunicação, as instituições de ensino e a indústria cultural), bem como utiliza-se da análise de uma série de políticas sociais de segregação, estigmatização e de conciliação ocorridas nos Estados Unidos (leis Jim Crow), África do Sul (apartheid) e Brasil (democracia racial), para exemplificar as questões acerca do racismo estrutural.

Na construção da argumentação de seu estudo, Silvio Almeida utiliza-se de uma vasta bibliografia nacional e internacional, aliando clássicos estudos estadunidenses, europeus e nacionais do século XX como de Michel Foucault, Ângela Davis, Florestan Fernandes, com as investigações de importantes pesquisadores dos chamados movimentos decoloniais e póscoloniais, como Frantz Fanon, Aníbal Quijano, Achille Mbembe, Kabengele Munanga, Walter Rodney, entre outros.

$\mathrm{Na}$ esteira das questões apresentadas pelo pesquisador, Silvio Almeida nos apresenta um complexo estudo que não somente se circunscreve em uma análise histórico-social do 


\section{novitt

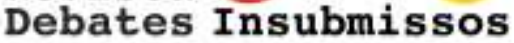

racismo enquanto fenômeno estrutural. Almeida evidencia que as questões descritas e muito bem analisadas ao longo dos séculos XIX e XX possuem enorme implicação na atualidade.

Sobre as exemplificações de sua obra sobre os impactos do racismo nos dias atuais, certamente suas discussões sobre as questões que se referem a representatividade merecem destaque. Almeida, ressalta que a representatividade de sujeitos negros em espaços de poder e prestigio social, seja em centros de difusão ideológica como os meios de comunicação e a academia não correspondem suficientemente como formas de combate ao racismo, pois, segundo o pesquisador, a representatividade acaba por esbarrar em "uma visão delirante e perigosa" da meritocracia, ou seja, para muitos sujeitos:

[...] a existência de representantes de minorias em tais posições [de poder] seria a comprovação da meritocracia e do resultado de que o racismo pode ser combatido pelo esforço individual e pelo mérito. Essa visão, quase delirante, mas muito perigosa, serve no fim das contas apenas para naturalizar a desigualdade racial" (ALMEIDA, 2020, p. 109).

Contudo, é inegável as contribuições da representatividade, sobretudo, se esta for entendida enquanto um primeiro passo para a construção de uma sociedade antirracista. Para Almeida, a representatividade pode ter dois efeitos importantes no combate à discriminação:

1.Propiciar a abertura de um espaço político para que as reinvindicações das minorias possam ser repercutidas, especialmente quando a liderança conquistada for resultado de um projeto político coletivo;

2.desmantelar as narrativas discriminatórias que sempre colocam minorias em locais de subalternidades. Isto pode servir para que, por exemplo, mulheres negras questionem o lugar social que o imaginário racista lhes reserva (ALMEIDA, 2020, p. 110).

Neste sentido, a representatividade dever ser tomada enquanto um resultado de luta política e social. Contudo, como Almeida ressalta, a partir das palavras de Charles Hamilton e Kwane Ture "visibilidade negra não é poder", ou seja, “[...] o racismo não se resumo a um problema de representatividade, mas é uma questão de poder real" (ALMEIDA, 2020, p. 110).

$\mathrm{Na}$ atualidade, podemos observar, a partir dos noticiários nacionais e internacionais, dos movimentos negros como o Black Lives Matter, que obras como esta, correspondem a uma demanda social que visa a destituição do atual sistema social pautado em ideologias, 
políticas e sistemas econômicos construídos sob uma estrutura racial desigual, segregadora e excludente. A obra de Silvio Almeida, pode ser entendida como um farol que tece um novo caminho para uma sociedade que compreende sua atual estrutura e paute-se em reconstrui-la a partir de pressupostos antirracistas. Como bem destaca o pesquisador Marcelo Paixão, Racismo Estrutura de Silvio Almeida “[...] é uma importante contribuição de um jovem intelectual negro para o avanço do pensamento social do país rumo a novas abordagens mais críticas e ousadas sobre os antigos, novos e novíssimos problemas enfrentados pelo Brasil" (PAIXÃO, 2020).

Submetido: 07/12/2020

Aprovado: 30/08/2021 